\title{
Management Processes in Technical-economic Design, Decision-making, Fractals and Market Bubbles
}

\author{
V. Beran \\ Keywords: decision making, management, cellular automata, fractals, market bubbles, technical economic design, simulations, process and \\ regulation, steering process and management.
}

\section{Introduction}

Technical-economic processes are generally events running in time and space (factual space of proposal opportunities). Most of these events are related to their economic life-cycle and their technical-economic structure. In their classical analytical form, models of technical-economic events are based on a description of systems of equations, matrix models, or models based on quantitative formulas and use of differential or difference calculus if qualitative descriptions are needed. There are also other models, based on graph theory (Demel, 2002), symbolical logic and sets (Vlcek, Beran, 1984) and also on cellular automats (Wolfram, 2002), or symbolic verbal oriented models.

Existing models operate mostly on the basis of analytic concepts of description, quantitative or selected qualitative relations. However most of them do not contain built-in decision-making mechanisms or connections to possible operational management or steering interventions that can be used in a model that enables design. A large range of models are isolated from the concept where a model may be a subject of experiments like changes of parameters, or more likely the adjustment of parameter structure. Let us use other terminology. Models used in practice restrict their own possible goals and describe almost exclusively already existing (known) reality. The approach resembles a static calculation that has to prove the stability of an already existing structure (scheme). It is worth dealing with this approach, while very often a finished (ready) design of a technical product or proposal has to be proved or made efficient (ad post) by an economic calculation. Commonly created post design calculations like total construction costs (TCC), life-cycle cost (LCC), revenue per year (ROI), feasible construction time or cash flow schedule, diverse deadlines, or other quantifiable parameters have to appreciate existing design parameters, no matter how suitable the design might be if there were methods influenced by the conceptual starting position. These situations may be called technical-economic design ex post. The economics of such situations is a procedure that affirms but does not create. Design, however, involves creating new possibilities and new spaces, or functions. The economics of design of new techni- cal solutions should solve and anticipate. It should be aimed at possible future solutions and this is activity ex ante (Beran V., 2002) Modern design has to create values to which Homo economicus is willing to award a purchase price. This is not a question of modern trends but of the ability to create added value. Any reproduced and repeated solutions that are available in many variations and are a matter of mass production have only a decreasing ability to create some added value and in its ultimate implication, profit.

On the other hand Homo technicus generally aims to present his technical brilliance and skills. A result that might be called an optimal depends for most projects on a wide range of asserted decisions in time and technical-economic space (Bayes, 1763). Each particular decision (and sequence of decisions) should be chosen optimally. This is a so-called necessary condition of optimality in the time ongoing process.

Applied mathematics offers its own ways in terms of model ranking (e.g. linear, non-linear, static, dynamic, etc.). Economics and organization of production processes uses its own instruments. Graph theory, mathematical models from elementary linear models to complicated dynamical behaviour of non-linear economic processes (with cycles of balance and deterministic chaotic states, (Kubík, 1982)) offer interesting applications in economics.

Engineers and economists - using simple modelling tools like timetables, budgeting, costing, and enterprise financial and management planning - should know, however, how to incorporate the tools they are using into the hierarchy of sophistication, utility and benefits. The field of economic and social sciences certainly offers a high number of views and impulses. The services provided by industrial economics (microeconomics) depend on a range of complicated instruments. Utility values are transformed by means of organization and economic models into the consumption. If the model is well designed these transformations are positive. However, badly designed model may lose many opportunities and values, waste resources and effort.

A good model of reality is our goal, an apposite, useful reality model. The right model leads to represents a true picture about functions, opportunities and, designed added values. We are in point of fact seeking for models that 
represent and refer to those qualities that have can create innovative design, create an added value over a technical-economic common (standard) design and solutions. Economics, unlike technical science, presents values that are partly impermanent (unsustainable). Values change in time, vanish and others come into view. Economics requires a description of universal attributes on the one hand and changes its involvements and objectives from one time to another. In its nature it is the technical piece of work that creates the long-term sustainable values of the economic life-cycle of every region, enterprise and city.

For technical, managerial or technological reasoning of economic issues, a comprehensive definition of the components (processes, etc.) is needed, followed by the ability to define theses on the basis of a model. The whole range of economic problems defines its processes (elements) simultaneously with a solution method of the given task. In economic applications, the solution and the chosen definition of the problem generate a balanced facet. Suitable illustrative examples of the above mentioned situation were and still are many different applications of production scheduling, time scheduling models like CPM, MPM, RAMPS, dynamic time schedule, etc. The same situation also exists in other technical-economic disciplines that use quantitative methods, theory of stores, theory of renewal, structural analyses, theory of decision-making, etc. A definition of elemental syntactic process - components is just the starting point of each new task. However, every single application that is born in technical-economic disciplines is endangered by an incorrect or incomplete definition of the elemental components or processes. In a broad range of applications we realize that a number of attributes of content quantities and content quantities themselves have to be changed. A whole range of tasks fail to create the sort of internal boundaries that would prevent solutions of the task or solutions that lead in an unsustainable direction. Indeed these above mentioned risks are generally valid. A technical-economic task rarely works well on the basis of a purely physical form. The economic effect may be proved only with difficulty by means of other controlling models. The proof usually runs on the basis of expert judgments. Mistakes that are dragged in often difficult to detect, and we are looking for sustainable long-lived solutions.

Under conditions for sustainability it is desirable to define not only sets of activities (sets of processes) that operate as substance (material) transforming controlled models $(\mathbf{P})$, and also comprehensive (derivative) structures of a controlling character, i.e. a set of controlling models (steering models) (L).

Let us delineate the synergetic symbiosis of $\mathbf{P}$ and $\mathbf{L}$ as a process of management (M), (in Vlček, J., Beran V.,1984, Beran, 1997 and 1999). To simplify the situation, the operating model will be described only in the space of quantitative derived components created on the basis of so called networked processes $\mathrm{P}_{\mathrm{i}} \Rightarrow \mathrm{N}_{\mathrm{i}}<\mathbf{A}, \mathbf{K}>$, where $A$ represents a set of components with their physical descriptions $U$, dependences in time $\mathcal{D}$ and a set of dependences of quantitative character $Q . \mathbf{K}$ is an interconnection set (causality) between components with their set of physical descriptions V, construction of connections $\Delta$, and starter of connections $\varepsilon$.

In symbolic form, a notation of management appears as:

$$
M_{N}=\left\{\begin{array}{c}
M_{i}^{N} \mid \mathbf{M}=\left\lfloor\left\langle\varphi(t, \mathbf{P}, \mathbf{L}) \mid \mathbf{D}^{\sim}\right\rangle \mid \mathbf{K}\right\rfloor, \mathbf{P}=\langle\mathbf{A}, \mathbf{K}\rangle \\
\mathbf{A}=\langle\mathbf{U}, \mathcal{D}, Q\rangle\rangle \\
\mathbf{K}=\langle\mathbf{V}, \Delta, \boldsymbol{\varepsilon}\rangle \\
\mathbf{L}^{\prime}=\langle\bullet\rangle \\
\mathbf{K}^{\sim}=\left\langle\mathbf{V}^{\sim}, \Delta^{\sim}, \varepsilon^{\sim}\right\rangle \\
\mathbf{D}^{\sim}=\left\langle\mathbf{F}^{\sim}, \operatorname{dim}(\mathbf{h})\right\rangle
\end{array}\right\}
$$

An operating process on the level of networking process $M_{i}^{N}$ is executed only if we put aside and separately define decision making procedures for selection of the variant and alternative solutions of possible operating (steering) management interventions created by means of $\varphi(t, \mathrm{P}, \mathrm{L})$, selected by decision-making mechanisms $\mathbf{D}^{\sim}$. Deciding is necessary for execution of targets. Without it an operational leading process might only use regulative rules for decision-making procedures $D^{\prime}$ inside $L_{(\text {). }}$ provided that the operational leading (steering) process was created on a sufficiently efficient level, i.e. it would be on the level $\mathbf{L}_{\mathbf{s}}$ (so-called planned level). A lower elementary level $L_{A}$ and causal leading process $L_{K}$ (on the basis of casual relations) does not offer any chance to prevent the operational process from transitioning to degenerative states. The network shaped (designed) process is quite arduous for reasons of scheduling (steering). It requires that the steering (leading) process will substitute (virtually describe) the elements of reality ( $\mathbf{P}$ - process), will be able to influence the structure and at the same time to control the model of regulative decision part $\mathbf{D}^{\prime}$. The decision component of control block $\mathbf{D}^{-}$is part of the management model and in its frame was also designed for this function. We suppose that it is stable in the developed scheme (1) and that a component of information transmission $\mathbf{K}^{-}$is able to implement in time all necessary communication about managerial information and interventions. $\mathbf{K}^{-}$has to secure the transfer of all necessary information for the needs of the steering model $L_{(\cdot)}$.

Let us attempt to reply briefly to some questions concerning to entry (1) from the time-oriented viewpoint on decision descriptor D- It would certainly be interesting to know whether, in designing a technical work, the decision processes have certain specific properties in their use. It is important to comprehend this, especially when we are looking for explanations and causes for an unexpected project development. The number of successful or unsuccessful outcomes of engineering projects from the hands of Homo economicus or technicus depends on the presence or absence of a rational vision. The very character of steering space, its structure in time, may be so specific for applications in engineering design non-homogeneous that unexpected disturbance of the technical work sustainability life-cycle occurs. The sequence of decision-making in steering processes (i.e. management) may have other rules and places for implementation than have usually been envisaged until now. The reasons are usually economic limits and indicators; however, their duration is mainly only a fragment of the total technical life-cycle of a designed project. Application of designing might have proceeded differently if better rules had been applied for selection of their solutions (decisions) inside a steering process (L), at least better in terms that we use to thing about these D rules. This is the main reason why this article was written. 
Let us pose several fundamental questions:

1. Is the steering area for decision-making homogeneous?

2. Does non-homogeneous decision-making implementation of an environment (space, area) influence the decision steering process $\mathbf{D}^{\sim}$ ?

3. To what extent is decision process $\mathbf{D}^{\sim}$ in time strata $t_{x}$ affected by the previous decisions in the former time layer?

4. To what extent will be decision processes $\mathbf{D}^{-}$in time strata $t_{x+n}$ (further future) affect decisions in a time nearer to layer $t_{x}$.

Before we try to reply to this cluster of questions, it is desirable to elucidate the importance and utility of such search of answers. Homo economicus or technicus for many generations worked on technical solutions and judged them mainly intuitively.

Nowadays the entire contrivance of public competitions in the EU, the USA and many other countries is quite consciously based more or less on mechanisms that assume a homogeneous decision area. The basis of Bayes probability theory (Bayes, 1763) was extensively applied for technical-economic decision-making in the second half of the $20^{\text {th }}$ century (Raiffa, Schleifer, 1961).

Consciously searching for new productive techniques to protect decisions from unfavourable judgements, working with enhanced data or facts, we may be critical of the existing methodological situation. The course and usage of methods practiced for technical-economic project design will necessarily change. On the basis of knowledge of the model a technician and an economist uses or can freely create steering measures (interventions) in the sense of $\varphi(t, \mathbf{P}, \mathbf{L})$ in (1). More sophisticated methods are under development (simulation, goal parameterisation, optimisation, construction of scenarios, etc.).

For the purposes of further explanation it will not be necessary to distinguish among particular phases or sophistication in the description of a real process $(\mathbf{P})$ or steering processes (L). Completing to a model that is able to generate interventions carrying (propagating) changes from the steering level to the realisation level we have marked in the previous sentence as $\mathbf{M}$. Tools for formation of steering interference $\varphi(t, \mathbf{P}, \mathbf{L})$ may, without requirements for determining of their robustness or suitability, are illustrated as follows:

- search for satisfaction of goals by means of solutions regardless of restrictive conditions, we will use the symbol goal conditioned by process parameters, see (la),

- the search for solutions on the basis of simulations of chosen parameters in determined boundaries, will be written as simul (1b),

- the search for solutions by virtue of the factual conception of the future solution along separate stage scenarios, marking decant scen $_{1}$, scen $_{2}, \ldots$ (see (1c)),

- the search for an optimal solution with reference to setting restrictive conditions is marked optim (see (1d)),

Therefore, we cannot speak about a single management model class. A whole range of approaches exists, which differ in evidence and efficiency.

Among the first class model we will rank models changing the goal objective value of process $\mathbf{P}$ by means of selected parameter $x_{i} \cdot$

$$
M_{\text {goal oriented }}=\left\{\begin{array}{cc}
\mathbf{P} & \left(x_{1}, x_{2}, \ldots, x_{n}\right) \\
\text { goal } & \mid x_{i}
\end{array}\right\} .
$$

The second model types for creating steering intervention for management are models based on simulations and parameterisation of calculations of changes in particular input values. Simulation is universally directed at the behaviour pattern from the standpoints of changing parameters that describe process $\mathbf{P}$

$$
M_{\text {simulation of steering interventions }}=\left\{\begin{array}{cc}
\mathbf{P} & \left(x_{1}, x_{2}, \ldots, x_{n}\right) \\
\text { simul } & \left(x_{i} \leftrightarrow(a, b), x_{j} \leftrightarrow(c, d), \ldots\right)
\end{array}\right\} .
$$

The third class of model description engages models with scenarios as a starting point for calculations of steering interventions. Steering scenarios will be understood as a sequence developed in time and space, realized on the basis of a process $\mathbf{P}$, and will be written down as

$$
M_{\text {scenario of steering interventions }}=\left\{\begin{array}{cc}
\mathbf{P} & \left(x_{1}, x_{2}, \ldots, x_{n}\right) \\
\mathbf{s c e n}_{1} & \left(a \rightarrow x_{i}, b \rightarrow x_{j}, \ldots\right)
\end{array}\right\} .
$$

The fourth model class will be models using optimisation as a supporting technique. By virtue of optimisation function $\mathbf{g}(\bullet)$ optimal arguments $\mathbf{x}^{\circ}$ are searched. Accomplishment of steering management intervention restricted on process $\mathbf{P}$ may be written down as

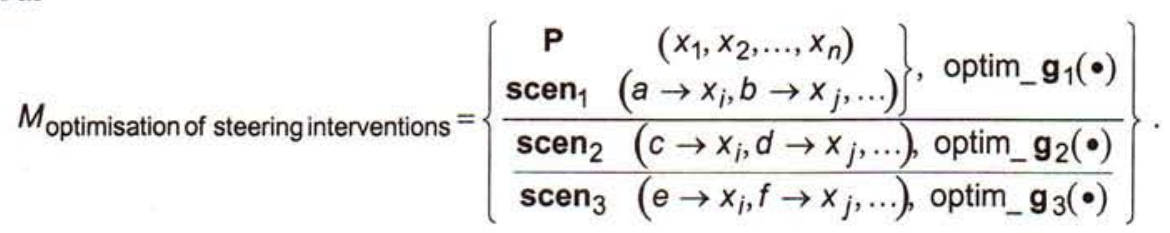


Practical modelling of steering intervention for management has not a uniform character and does not rely on a single theoretical or practical interim theory.

The basis of any management model remains process. A description of the model can take various forms. An ideal pedagogical form is description by means of a system of equations (linear, non-linear, ordinary differential equations, etc.) that are well-known in classical mathematics. In economic practice there are many situations where a description of relevant processes is currently solved by means of data and calculation built-up, for example, into databases. In most cases, it from the mathematical viewpoint this involves a small system of linear equations. Recording these in mathematical notation, however, would be too rigid to provide evidence for exact interpretation is limited from the economic point of view. Links between COMPUTER-AIDED DESIGN and CAM are currently made by relating a chart (drawing) and related calculations (most often for economic reasons), which describe sophisticated processes, and these are not immediately presented as a classical mathematic approach.

This paper is an attempt at generalization. The author considers as a process any technical-economic presentation of reality, and he considers as steering models any abstract description of the reality of processes that is employable for elaborating management interventions of these processes. In this sense there is certainly one management trend that exploits modelling as an instrument for generating steering proposals. Assumption of homogeneous application fields providing production resources and application of continuous space and time can be very limiting, if not misguiding.

The decision process $\mathbf{D}=\langle\mathbf{F}, \operatorname{dim}(\mathbf{h})\rangle$ mentioned in notation (1), used in processes $\mathbf{P}$ (suitable for be evaluation of real situations), or $\mathbf{D}=\left\langle\mathbf{F}^{\sim}, \operatorname{dim}(\mathbf{h})\right\rangle$ in the course of $\mathbf{L}$ applications for steering processes requires completion of the relevant area homogeneity within which the solution, created from $\varphi(t, \mathbf{P}$, L), can be implemented.

The impression that is feasible to break away from the existing mathematical theoretical rudiments will not however be correct. Even in modelling of $\mathbf{P}$ and $\mathbf{L}$, the elaborated model potential does not represent substitutable man-years exertion. However, implementation and propagation of decisions (implementation of decision interventions) may be done more carefully, if we are aware of the complicated application area.

\section{Decisions on the basis of $\mathbf{D}_{\alpha=\alpha}$ and shaped decision space}

In the sense of record (1) there is the real manufacturing or investment process $\mathbf{P}$, which capitalizes on an existing market and produces volume parameter $Q$ (here filling the a defined market area with products). So the investments intended to make use of demand in an economic area, for example, dwellings in time periods $t=1,2, \ldots$ and separate areas $A, B, C, \ldots$.

Existing demand for goods in time $t_{0}$ is filled by volumes of initial investment houses and lands in $A, B, C, \ldots$. However, the filling will be limited by the available resources (capital). For simplicity, we can suppose that the market space can from the voluminous point of view $(Q)$ be filled and have the value 1 , or be unfilled and have the value 0 . We can write that the management decision will be $A^{Q}=1$, or $A^{Q}=0$. In this situation we can write the vector of the starting action state for $\mathbf{P}_{t=0}(A$, $B, C, \ldots)$ as vector $(1,1,1,1,1,1,1, \ldots)$, when denoting the fully filled-out space of potential needs. The vector initialising state processes $\mathbf{P}_{t=0}=(0,0,0,0,0,0,0, \ldots)$ expresses an empty space of possible needs (for example of housing in the initial time period and sites $A, B, C, \ldots$. Supposing that the steering process is sketched in such a way that it evaluates a positive situation of the state at the given time period $t$ and determines realization of new capital assets there, where segment area $A, B, C, \ldots$ has been reordered (sorted) into the importance-reflecting chain for a decision-maker according to his investment interests, for the past time period $t-1$ in the newly ordered areas $M, N, O$ (reveal $M$ as neighbouring left, $N$ is the position of the decision maker, $O$ neighbouring right).

The past might acquire values and be written as

$$
\begin{aligned}
& \mathbf{P}_{t-1}=\left(\ldots, M^{Q}=1, N^{Q}=\#, O^{Q}=1, \ldots\right), \\
& \text { or more concisely as } \\
& \mathbf{P}_{t-1}=(\ldots, 1, \#, 1, \ldots)
\end{aligned}
$$

or

$$
\begin{aligned}
& \mathbf{P}_{t-1}=\left(\ldots, M^{Q}=0, N^{Q}=\#, O^{Q}=0, \ldots\right), \\
& \text { or briefly } \\
& \mathbf{P}_{t-1}=(\ldots, 0, \#, 0, \ldots)
\end{aligned}
$$

where \# is used as a symbol for both values 0 or 1 .

Rule $\mathbf{D}^{\sim}$ can be reduced to the statement, if in the triad of processes $\mathbf{P}$ holds - $(M, N, O, \ldots)$ in the previous time strata

$$
\mathbf{P}_{t-1}(M)=\mathbf{P}_{t-1}(O)
$$

then

$$
\mathbf{P}_{t}(N)=0,
$$

in all other cases has the value of

$$
\mathbf{P}_{t}(N)=1 \text {. }
$$

Further we will denote the presented decision rule as $\tilde{\alpha}=\alpha$

Situations conforming to (2) and (2a) will not reckon area $\mathbf{P}_{t}$ as free for implementation of investments in the time period $t$ (puts in decision maker position 0 ). Otherwise the case investment admits (will insert 1). In the other scheme the conditions are displayed as a schematic table, see Table 1 (lines are time, columns are areas of realization). The positive solution (investor is willing to invest) comes into being, when it is valid that the market is implemented in the past period investment partly in the neighbouring areas (segments) (in Table 1 marked bold 1 substitutes yes, \# substitutes any).

Table 1: Decision rule, result action

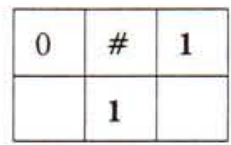

or

\begin{tabular}{|l|l|l|}
\hline 1 & $\#$ & 0 \\
\hline & 1 & \\
\hline
\end{tabular}

If it is valid for the following time step that (market, investment trust, competitors,..) who in the previous period did not make any investments in the neighbouring segments, then $a$ 
decision-maker himself arbitrates likewise negatively (see Table 2), regardless whether he himself has already invested into the given area.

Table 2: Decision rule, result no action

\begin{tabular}{|l|l|l|}
\hline 0 & 0 & 0 \\
\hline & 0 & \\
\hline
\end{tabular}

or

\begin{tabular}{|l|l|l|}
\hline 0 & 1 & 0 \\
\hline & 0 & \\
\hline
\end{tabular}

In other words a decision-maker invests (take positive decision), when there has not yet been full investment in the surroundings, i.e., under the situation $(\ldots, 0, \#, 1, \ldots)$ or $(\ldots, 1, \#, 0, \ldots)$.

\section{Implementation of a fully new solution for a fully vacant market}

Let us supposed that the solution for which a decision-maker decides is a new solution on a fully vacant demand market. For example we have a fully new product like a mobile phone on a totally fixed-line phone market or a PC on the mainframe computer market a decade or two ago. Moreover, the market area will not be limited in the near future by any boundary conditions of demand, not even by market saturation. Diagrammatic calculations according to (3) to (5) are shown in Table 3 (a segment from a wider calculation of how the market will fill up in time (vertical axis) and the space for steering decisions for management shows the demand opportunities (horizontal axis)).

Applied decision criterion $\mathbf{D}_{\alpha=\alpha}^{\sim}=\langle\mathbf{F}, \operatorname{dim}(\mathbf{h})\rangle$ is a criterion of two dimensions, like those described in (3), (4), (5), where $F_{1}$ tests whether in the last time period the investment action on the left of the decision-makers area occurred and $F_{2}$ tests whether in the past time period the investment action to the right of the decision-maker area occurred. The metrics of evaluation $\operatorname{dim}(\mathbf{h})$ are given in this case as 1 and 0 .

Table 3: Decision structure in time and decision area

\begin{tabular}{|c|c|c|c|c|c|c|c|c|c|c|c|c|}
\hline Time / Space & \multicolumn{10}{|c|}{ Decision making area (interventions) } \\
\hline $\begin{array}{c}\text { Starting period } \\
t=0\end{array}$ & 0 & 0 & 0 & 0 & 0 & 1 & 0 & 0 & 0 & 0 & 0 & 0 \\
\hline $\begin{array}{c}\text { Consequence } \\
\text { decisions } t=1\end{array}$ & 0 & 0 & 0 & 0 & 1 & 0 & 1 & 0 & 0 & 0 & 0 & 0 \\
\hline$t=2$ & 0 & 0 & 0 & 1 & 0 & 0 & 0 & 1 & 0 & 0 & 0 & 0 \\
\hline$t=3$ & 0 & 0 & 1 & 0 & 1 & 0 & 1 & 0 & 1 & 0 & 0 & 0 \\
\hline$t=4$ & 0 & 1 & 0 & 0 & 0 & 0 & 0 & 0 & 0 & 1 & 0 & 0 \\
\hline$t=5$ & 1 & 0 & 1 & 0 & 0 & 0 & 0 & 0 & 1 & 0 & 1 & 0 \\
\hline$t=6$ & 0 & 0 & 0 & 1 & 0 & 0 & 0 & 1 & 0 & 0 & 0 & 1 \\
\hline$t=7$ & 1 & 0 & 1 & 0 & 1 & 0 & 1 & 0 & 1 & 0 & 1 & 0 \\
\hline$t=8$ & 0 & 0 & 0 & 0 & 0 & 0 & 0 & 0 & 0 & 0 & 0 & 0 \\
\hline
\end{tabular}

The input data line at the starting time, $t_{0}$ in Table 3 and the first line in Fig. 1 are followed by the generated decisions (solutions) on the basis of decision criteria $\mathbf{D}_{\alpha=\alpha}^{\sim}$ refer to lines $t=1,2, \ldots$ (in Table 3 ) are graphically illustrated in Fig. 1 (calculation created by MS Excel). For clarity, a particular area with valuation yes $=1$ is introduced as a dark (red) circumscribed field, and areas with value $n o=0$ are presented as clarity light (green) fields without a frame. In the logic of notation (1) we understand solutions as an area where fulfilments were activated. Activity $\mathbf{A}$ has placed there qualities and quantities $\langle\mathbf{U}, \mathcal{D}, Q\rangle$, e.g., investment, capital assets, housing constructions, etc.

\section{Interpretation}

The results in Table 3 and in Fig. 1 call for attention and a deeper interpretation of several interesting facts:

1. The action area on the basis of decision-making criteria $\mathbf{D}_{\alpha=\alpha}^{\sim}$ is not homogeneous. If we are at the top of the solution pyramid (in the time sequence from $t=1$, and column $B W$ in Fig. 1) the possibilities of factual expansion of the $\mathbf{P}_{B W}$ element in time (column in Table 3 ) are considerably predetermined. The whole area of the future development for the factual $\mathbf{P}(B W)$ series in Fig. 1 creates an empty set in time. In other words, a new technical solution does not create a substantial development chance; this is initially exploited mostly in related branches of business. Dispersion in time has its own rules and characteristics of diffusion.

2. In the area of solution dispersion in the series of capital action blocks (on the basis of $\mathbf{D}_{\alpha=\alpha}^{\sim}$ application) relatively extensive prohibitive areas without feasible implementation of any action are formed. In economic theory, the term market bubbles has been often used in the recent years. In the presented situation we can talk about generating such market bubbles in terms of inaccessibility or non-feasibility areas for decision implementation.

3. Each area of implementation for capital activity has a different life-cycle in time. If individual series of actions $(A, B, C, \ldots, M, N, O, \ldots$, see vertical column in Figs. 1, 2, $3, \ldots)$ are followed, we recognise that we have different ground schemes for the economic survival of actions. Capital steps that we interpret here in a simplified manner may be vital in its life-cycle only if and when, if their cyclical renewal occurs. However, the renewal has different (time) cycles and will offer good conditions for yields in, e.g., relatively irregular time cycles, in the opposite case, capital spending the on action must be terminated.

4. The lifetime of on activity in area $X$ is not given only by the life-cycle of the process $\mathbf{P}(\bullet)$, or by means of standards for on steering process $\mathrm{L}(\bullet)$. It is conditioned by decision criterion $\mathbf{D}^{\sim}$ and its mechanism accepted for the steering area and, vice versa for management of the task. It is not difficult to prove that almost every criterion forms another fractal space for exercising decision use in time and place.

5. A decision in some of the places $(A, B, C, \ldots, M, N, O, \ldots)$ in time $t$ will in future time periods influence a growing spectrum of realization areas. See Fig. 3, in $(t+1)$ there are only 3 areas of realization in prospect, in $(t+2)$ there 


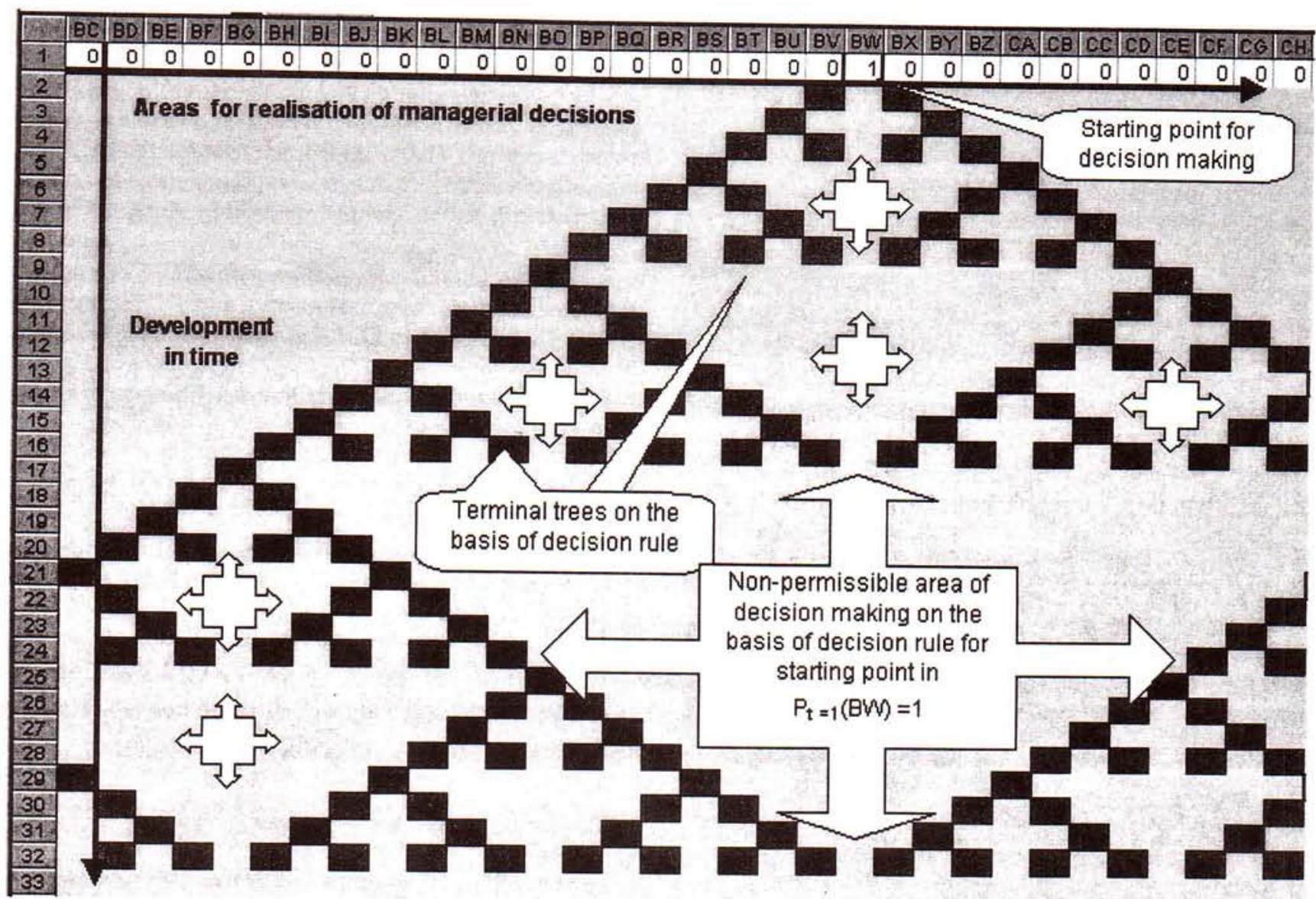

Fig. 1: Calculation of steering management decisions on the basis of decision rule $\mathbf{D}^{\sim}$ in time and implementations areas

are 5 possible places of realisation, and in $(t+3)$ there exist 9 recommended places of realisation.

6. Decisions in each area $(A, B, C, \ldots, M, N, O, \ldots)$ are affected by situations from past time periods by a growing spectrum of implemented decisions, $3,5,9, \ldots$ These are schematic displayed in Fig. 2.

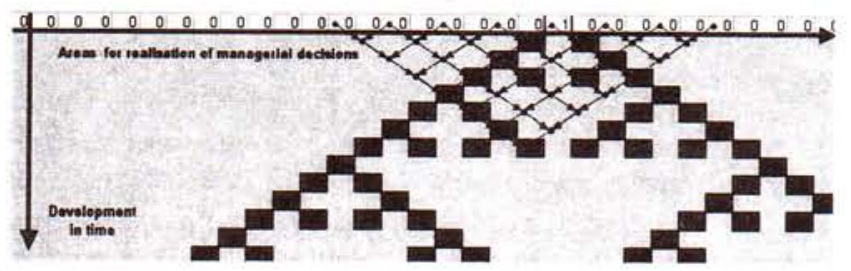

Fig. 2: Decisions that will influence an element in the eight's time strata (concentration of influences from preceding decisions)

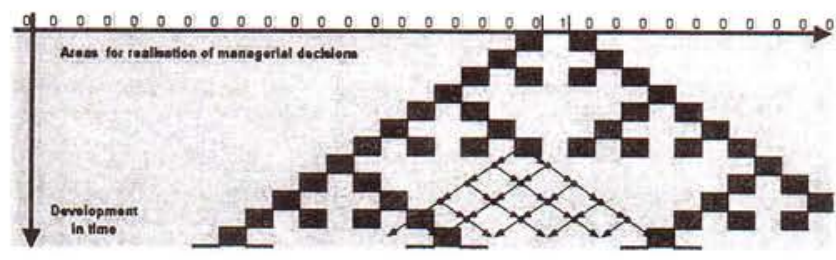

Fig. 3: Diffusion of decision-making consequences on strata and areas of realisation followed in time
In area of non-permissible actions according to criterion D , actions of another identical type cannot start. Each intersection of decision rules is a new decision-making exercise and a new application example of the fulfilment of steering area and time.

\section{Implementation of solutions on a completely full market}

The starting area of actions $\mathbf{P}(\bullet)$ at time $\mathrm{t}=1$ is referred as a starting fields set, put into the model as $(A, B, C, \ldots, M, N, O$, $\ldots, X, \ldots)$. If such a set is totally engaged, i.e. for the action area it is valid at $t_{0}$ as $(1,1,1, \ldots, 1)$, it is not possibile to invest in the future (on the basis of criteria $\mathbf{D}_{\alpha=\alpha}^{\sim}$ ). However, maximum effort in $t_{0}$ withholds all potential capital assets in the given areas in the future. The area of implementation remains an empty set for all time.

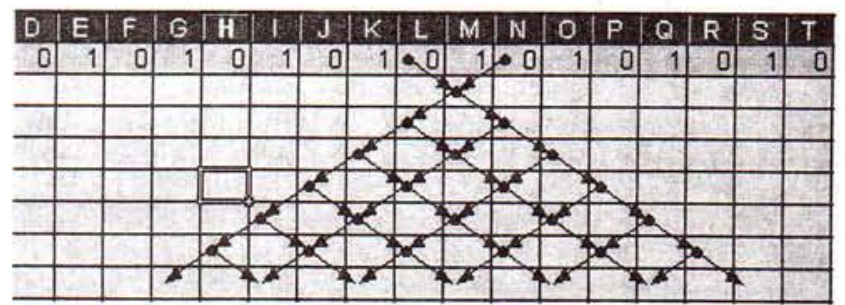

Fig. 4: Starting activity of type $(0,1,0,1,0, \ldots)$. The steering area is an empty set for implementation of criteria $D_{\alpha=\alpha}$. 


\section{A half-saturated market}

The starting area of actions $\mathbf{P}(\bullet)$ in time $t_{0}$ may be half-saturated, which means we will write

$$
\mathbf{P}_{\mathrm{t}}(\bullet)=(1,0,1,0, \ldots) \text {. }
$$

Employment of capacity hold back, as well as previous situation, possibility to implement any further actions in the given area (on the basis of the criterion $\mathbf{D}_{\alpha=\alpha}^{\sim}$ ). Fig. 4 represents data of a steering area that was half-saturated, type $(0,1,0,1,0, \ldots)$.

The preliminary conclusion, is that massive starting investment does not pave way to successful and sustainable investment or, e.g., productive market development, where the starting steering area presents a partly saturated set (robust filling of $50 \%$ of total capacity). In the course of decision rule we can find the variety of responses filling the steering area.

\section{A sporadically occupied steering area}

Examples of other types of starting areas $\mathbf{P}(\bullet)$ in time $t_{0}$ are shown in Figs. 5, 6 and 7. Analyses of their technical-economic interpretation would be quite interesting. A further interesting question seems to arise. To what extent do steering models and decision-making as such influence the area (management area) at which technical-economic activities are accomplished? It would extend beyond the framework of this paper to deal with this difficult question. However, the calculations figured in the figures display confirm that it is a non-homogeneous feasibility area for management decisions, with the formation of bubbles in the space for decision implementation.

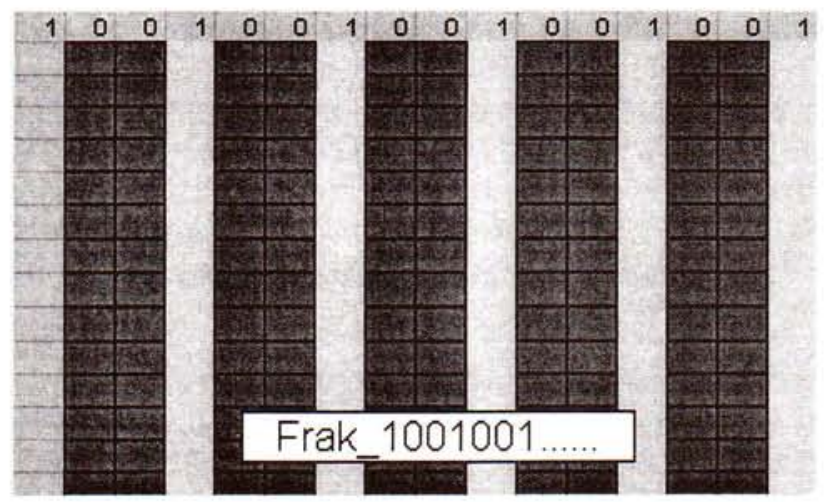

Fig. 5: Steering area and decision rule $\mathrm{D}_{\alpha=\alpha}^{\sim}$ and starting area at $t_{0}$ as $(1,0,0,1,0,0,1, \ldots)$

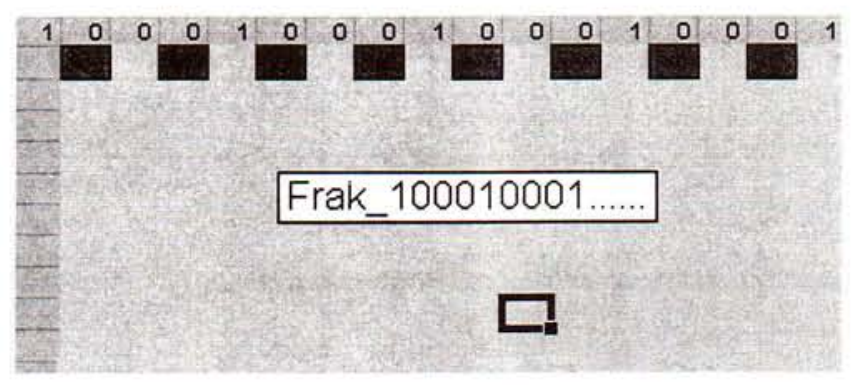

Fig. 6: Steering area and decision rule $D_{\alpha=\alpha}^{\sim}$ and starting area at $t_{0}$ as $(1,0,0,0,1,0,0,0,1, \ldots)$

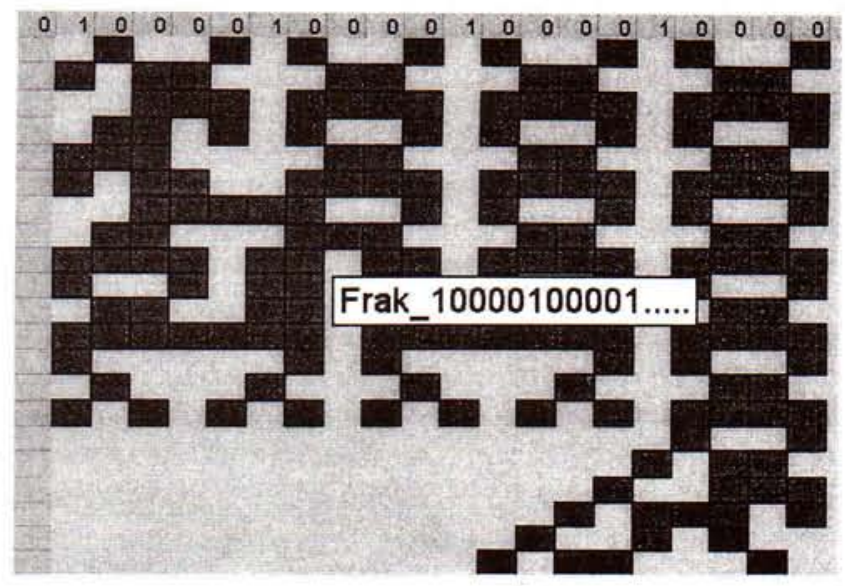

Fig. 7: Steering area and decision rule $\mathrm{D}_{\alpha=\alpha}$ for starting area at $t_{0}$ as $(1,0,0,0,1,0,0,0,1, \ldots)$

\section{Conclusion}

Existing economic and management theories of technical-economic processes are very often in practice based on the perception of homogeneity in the application space. A number of technical and economic projects are outlined under the condition that all areas of implementation of management decisions are homogenous and rules that were valid in analogous cases in the past will also be valid in possible future designs and projects. The purpose of this paper was to query such a conviction and indicate new possible directions in the development of the discipline. This involves a new orientation. The orientation will indicate new consideration and direction of thinking. After model interpretation of deterministic chaos in management it was necessary to see the whole series and passages of the area of technical-economic management in another light (Kubik 1982). Perhaps the entire series of educationally splendid statements and passages in textbooks have to be rearranged. In notation (1) the decision processes for selection of management interventions may be seen as a meta-expression. Seeking for principal differentiations and revisions may gain some more argumentation. The presumption of homogeneity in the decision-making area may coincide with all decision mechanisms. Competition evaluation, crisis management decisions in a complicated technical-economic project lead to new and newly-authorized doubts. It is, however, possible that it will be necessary ever in the near future to accept approaches and changes in interpretations of more powerful implementation of interferences between decision-making and implementation areas. The applications of fractals (Mandelbrot 1991) may provide an interesting stimulus for innovation.

\section{Acknowledgement}

This paper forms part of a research project of CTU in Prague at the Faculty of Civil Engineering: Management of the life cycle in sustainable development of construction, building enterprises and regions (MSM: 210000006), financed by the Ministry for Education, Youth and Physical Training CR. 
In the calculation the paper makes use of the methodological basis created within the project on: „Harmonisation engineering activities with EU (design method, and realization of building Life-Cycle according to EU ISO) " financed by the Grant Agency of the Czech Republic Prague 1, National Avenue 3.

\section{References}

[1] Mandelbrot, Benoit, B.,B.: Die fraktale Geometrie der Natur. Basel, Boston, Berlin: Birkhäuser Verlag, 1991.

[2] Kubík, S., Kotek, Z., Razim, M., Hrušák, J., Branžovský, J.: Teorie automatického ř́zeni II. (Theory of steering and automation). Praha: SNTL, 1982.

[3] Beran, V.: Modelovánív rízeni 10. (Modelling and Management 10). Skripta ČVUT. Praha: Vydavatelství ČVUT v Praze, 1997.

[4] Beran, V.: Modelovánív ř́zeni 20. (Modelling and Management 20). Skripta ČVUT. Praha: Vydavatelství ČVUT v Praze, 1999.

[5] Vlček, J., Beran, V.: Automatizované systémy řizení. (Automation and Steering Systems). Praha: SNTL, 1984.

[6] Tondl, L.: Hodnocení a hodnoty. (Metodologické rozměry hodnocení). (Evaluation and Values, Methodological Evaluation Dimension). Praha: Filosofia AV ČR, 1999.
[7] Beran, V.: Proč v ekonomice neplatí $1+1=2$. (Why Does Not Hold in Economics $I+1=2$. Public lecture). Veřejná přednáška FSv ČVUT v Praze 2000.

[8] Wolfram, S.: A New Kind of Science. Amazon, 2002.

[9] Demel, J: Teorie grafi. (Graph Theory) Praha: Academia, 2002.

[10] Beran V. a kol.: Dynamický harmonogram, elektronické rozvrhováni technicko ekonomických procesư. (Dymamic Time Charts, Electronic Scheduling of Resources of Technical-economic Processes). Praha: Academia, 2002.

[11] Raiffa, H., Schlaifer, R.: Applied Statistical Decision Theory. Cambridge, Mass.: Harvard University Press, 1961.

[12] Bayes, T.: Essay towards Solving a Problem in the Doctrine of Chances. Biometrika, Vol. 45, p. 293-315. (Reproduction of 1763 paper).

Doc. Ing. Václav Beran, DrSc.

phone: +420224354526

e-mail: beran@fsv.cvut.cz

Department of Economics and Management

in Civil Engineering

Czech Technical University in Prague

Faculty of Civil Engineering

Thákurova 7

16629 Prague 6, Czech Republic 